\title{
Acceptance of human papillomavirus vaccination and associated factors in the city of Resistencia, Argentina
}

\author{
Raúl M. Chaparro, M.D., ${ }^{a}$ Verónica Em Vargas, M.D., ${ }^{a}$ Liliana R. Zorzo, M.D., ${ }^{a}$ \\ Sebastián Genero, M.D., ${ }^{a}$ and Antonieta Cayre, M.D. ${ }^{b}$
}

\begin{abstract}
Introduction. In Argentina, every year, 3000 new cases of cervical cancer are diagnosed and more than 2000 deaths occur as a result of this disease. Human papillomavirus (HPV) is the main risk factor for cervical carcinogenesis.

Objectives. To establish the extent of acceptance of HPV vaccines and associated factors among legal guardians of candidate girls in an area of Resistencia, Chaco.

Methods. Qualitative and quantitative study. A single randomized sampling was done based on school enrollment lists. Guardians who reported making decisions regarding girls' health in 2012 were included. A structured questionnaire made up of four constructs was used to measure overall acceptability. The association between overall acceptability and sociodemographic outcome measures was assessed.
\end{abstract}

Results. The rate of acceptance was $46.6 \%$ (95\% confidence interval: 34.8-58.6). Among guardians, $84.2 \%$ were women; their mean age was 38.3 years old ( $95 \%$ confidence interval: $36.7-39.8)$. Religion was practiced by $86.8 \%$ (77.1-93.5), 55.2\% were Catholic and $44.8 \%$, Evangelical Protestants. Guardians with more than one candidate girl for the vaccine accounted for $18.9 \%$. Also, $85.5 \%$ referred having heard about the virus at some point, and $52.7 \%$ knew that a vaccine could prevent it. Acceptance was significantly higher among guardians of those girls who had received the first vaccine dose (OR: 8.02, 95\% confidence interval: 2.29-28.01, $p=0.0011$ ).

Conclusions. The rate of acceptance was low and no association was observed between sociodemographic and psychosocial factors and the decision to have girls vaccinated with the HPV vaccine.

Key words: immunization, tumor virus infections, papillomavirus infections, acceptance of health care.

http:/ /dx.doi.org/10.5546/aap.2016.eng.36

E-mail address:

Raúl M. Chaparro, M.D.: martinchaparro87@ gmail.com

\section{Funding:}

Ministry of Health of the Province of Chaco.

Conflict of interest: None.

Received: 04-29-2015 Accepted: 08-26-2015 success will depend on achieving a high level of coverage, which is strongly subjected to users' and health care providers' acceptance. ${ }^{2}$

In Argentina, the burden of this disease is not homogeneous and varies depending on the geographic location. It is very high among populations with a lower level of socioeconomic development. Additionally, regional mortality rates reflect such variability; in increasing order, as follows: South, Center, Cuyo, Northwest, and Northeast. ${ }^{3}$

The impact of this disease may be partly avoided by prophylactic HPV vaccination. It has been demonstrated that this intervention prevents $77 \%$ of cervical neoplasms associated with HPV serotypes 16 and 18, prevalent in cervical cancer (CC). ${ }^{4}$

Currently available vaccines in Argentina have proven effective and safe to prevent HPV serotypes 16 and 18 related lesions and to provide cross-protection against serotypes $31,33,45,52$ and 58, not included in the vaccine. However, its long-term effectiveness to prevent cervical cancer has not been fully demonstrated..$^{5-7}$ Common adverse effects are mild and include pain, swelling or redness at the injection site. Fever and nausea are also common, but these were not more frequent among girls who received the HPV vaccine than in other girls who received a placebo injection. These adverse effects usually resolve spontaneously in one or two days. ${ }^{8}$

According to the Extended Immunization Program established by the province of Chaco, the second dose of the HPV vaccine reached a coverage among the studied population of $24.55 \%$ in the first 
semester of 2012, a much lower percentage than what had been expected. Our hypothesis was that guardians' acceptance may be one of the factors associated to a low level of immunization coverage, explained by certain sociodemographic and psychosocial factors.

The general objective of this study was to establish the level of acceptance of the HPV vaccine by guardians of candidate girls in an area of Resistencia, Chaco, in Northeast Argentina.

Specific objectives were as follows: a) to establish the coverage of HPV vaccination in girls who are in the appropriate age group; and $b$ ) to explore the association between guardians' intention to have girls vaccinated and sociodemographic and psychosocial factors.

\section{METHODOLOGY}

\section{Type of study}

A descriptive, qualitative and quantitative study was conducted between April and October 2012.

Population: guardians who reported making decisions regarding girls' health (mother, father, legal tutor and/or representative), living in the sphere of influence of a primary care service in the city of Resistencia, Chaco, in 2012.

\section{Sampling}

A single randomized sampling was done based on school enrollment lists of 11 yearold female students. If girls had more than one guardian, the person responsible for making decisions about the girl's health was selected.

Guardians were invited to participate in school meetings based on a schedule established for each school. If a guardian did not attend, they were visited at home.

Analysis unit: guardians were randomly selected based on lists of 11 year-old girls included in the class lists of public primary education schools located in the sphere of influence of the city's referral health care center.

Exclusion criteria: guardians who were unable to speak or complete the questionnaire or who refused to participate in the study.

Sample size: from a total of 560 schoolgirls with a $60 \%$ prevalence of acceptability among guardians and an alpha error of 0.02 (according to scientific publications from Canada and the United States of America), ${ }^{9}$ the final sample was estimated to be 300 guardians.

\section{Method}

Source of information. Measuring instrument

A specially designed structured questionnaire made up of four constructs was used; it assessed overall acceptability by means of guardians' intention to have girls vaccinated. Each construct included three items measured using a Likerttype scale (1 to 5 ). 1 : strongly disagree; 2 : disagree; 3: neither agree nor disagree; 4: agree; 5: strongly agree. A pilot study was conducted to test the questionnaire. The measuring instrument showed an acceptable internal consistency of 70\% (Cronbach's alpha: 0.701). (Annex).

\section{Dependent outcome measure}

Overall acceptability. Overall acceptability was assessed using constructs based on the theory of planned behavior. The total score was obtained and a score of 50 points or more was used as a cut-off point; any score above 50 was deemed as accepting vaccination.

\section{Definition of constructs that make up vaccine} acceptability

- Intention: behavioral intention is the most direct factor, and closest to behavior.

- Attitude: an individual's positive or negative evaluation of self-performance of a particular behavior, which is made up of the individual's beliefs regarding the outcomes of such behavior and their assessment of these outcomes.

- Subjective norm: an individual's perception of social pressure to carry out or refrain from carrying out a particular behavior, which is made up of the individual's beliefs regarding what certain referent groups believe about such behavior and their motivation to comply with referents.

- Perceived behavioral control: an individual's perceived ease or difficulty of performing a particular behavior; it is assumed that it reflects both past experience and anticipation of hurdles and obstacles.

\section{INDEPENDENT OUTCOME MEASURES}

Sociodemographic factors of the guardian:

- Sex: female-male.

- Age: in years.

- Religion: practicing a religion or not. If affirmative, Catholicism, Evangelical Protestantism, Judaism, other religions.

- Education level: level of education attained, categorized into primary, secondary, tertiary, 
university or no education. According to the National Department of Information and Assessment of Education Quality (Dirección Nacional de Información y Evaluación de la CalidadEducativa, DINIECE), part of the National Ministry of Education, in 2010, more than $98 \%$ of male and female children aged between 6 and 11 years old in the province of Chaco attended school. Out of all students enrolled in Chaco, $25 \%$ were in the private sector. ${ }^{9}$

- Income level: family household monthly income in Argentine pesos, categorized into less than $\$ 1000$, from $\$ 1000$ to $\$ 2500$, from $\$ 2600$ to $\$ 4000$, from $\$ 4100$ to $\$ 6000$, and over $\$ 6000$.

- Presence of a family member with cancer: yes/no.

Factors related to knowledge

- Knowledge about HPV: yes/no.

- HPV vaccination coverage for the first dose: yes/no.

\section{Statistical analysis}

A univariate analysis was performed. Mean and standard deviation were estimated for quantitative outcome measures, while the ratio and 95\% confidence interval (CI) were calculated for qualitative outcome measures. A bivariate analysis was then developed to assess the relationship between qualitative outcome measures (overall acceptability) and sociodemographic outcome measures. The $\chi^{2}$ test was used to determine independence among groups. A $p$ value $<0.05$ was considered statistically significant. An unconditional logistic regression was done for the multivariate analysis.

The Epi Info ${ }^{\mathrm{TM}}$ and IBM SPSS Statistics version 21.0.0 (SPSS, Inc, Chicago, Illinois) software programs were used.

\section{Ethical aspects}

The study was not subjected to an assessment by a Research Ethics Committee because it was part of a pilot project for the implementation of HPV immunization managed by the Provincial Immunization Program called National Program for the Control of Vaccine-Preventable Diseases (Programa Nacional de Control de EnfermedadesInmunoprevenibles, ProNaCEI) as routine monitoring of vaccination coverage levels. Study participants were not exposed to any risk; notwithstanding, informed consent was obtained from those who voluntarily agreed to participate in the study. For data confidentiality purposes, the survey was completed anonymously, and anonymization mechanisms were established for outcome measures that could have identified participants. In addition, formal agreements were made between the Ministry of Education and the Ministry of Health regarding access to lists of schoolgirls.

\section{RESULTS}

Out of 12 selected schools (300 guardians), two refused to participate (80 guardians). The survey was completed by 100 guardians (75 women) from the remaining 10 schools (220 guardians). Twenty-three surveys were excluded from the analysis due to missing data. Surveys completed by 77 guardians were included for analysis; $84.2 \%$ of guardians were women with an average age of 38.3 years old. The expected sample size was not attained due to budgetary and logistic issues and, also, because of guardians' low response rate. In the end, the power of the study for this sample size was $64 \%$. Although lower than what has been usually reported, we believe that this is an acceptable power for an exploratory study.

As per the information provided by guardians, $46.1 \%$ (95\% CI: $34.5-57.9$ ) of candidate girls had received the first vaccine dose (Table 1).

In relation to the guardians' level of education, $21 \%$ had completed tertiary or university education, $51.3 \%$ had completed secondary education, and $25 \%$, primary education.

The rate of overall acceptance was observed to be $46.6 \%$ (95\% CI: 34.8-58.6).

Knowledge about the vaccine introduced in the national immunization schedule was associated with its acceptance, although such association was not statistically significant (OR: $2.21,95 \%$ CI: 0.87$5.62, p=0.09)$. HPV vaccination coverage for the first dose as reported by guardians was associated with acceptance; its OR was 4.08 (95\% CI: 1.56$10.68, p=0.003$ ) (Table 2).

Following a multivariate analysis, for the best selected model, only the coverage for the first dose (adjusted OR: 8.02, 95\% CI: 2.29-28.01, $p=0.0011$ ) was associated with overall acceptance, adjusted by knowledge about the HPV vaccine, knowledge about HPV, socioeconomic level, age, sex, family member with cervical cancer, candidate girls for the vaccine, and religion (Table 3).

\section{DISCUSSION}

Our findings show that overall acceptability of the vaccine was lower than what has been 
published by other authors, who observed a $60-70 \%$ acceptance rate in other countries, including Canada and the United States of America. Such difference in estimations may be partly explained by the low power of our study to detect differences. ${ }^{10-12}$

Based on survey respondents' sex and age, it was possible to observe that most guardians were middle-aged women, similarly to what has been described in other studies. This is because women are usually the ones responsible for making decision regarding girls' health. ${ }^{10-12}$

Other studies that analyzed the set of outcome measures, including age, education level, socioeconomic level, number of candidate girls and religion, found no statistically significant differences in terms of vaccine acceptance. ${ }^{12-14}$

However, some authors have stated that the level of education is associated with a higher adherence to immunization schedules..$^{10,15} \mathrm{In}$ a study conducted by Ogilvie et al. in 2010, parents with a higher level of education were less prone to give their consent to have their daughters receive the HPV vaccine $(63.3 \%$ versus $72.9 \%, p<0.01) .{ }^{10}$ In addition, a qualitative study done in Colombia observed that families with a higher education and socioeconomic level, represented by parents of boys and girls attending private schools, showed a greater critical capacity towards scientific information received, which translated into a clearly hesitant attitude towards information about the vaccine. ${ }^{16}$
TABLE 2. Bivariate analysis of studied outcome measures and overall acceptance among guardians. Resistencia, Chaco, 2012

\begin{tabular}{|c|c|c|}
\hline \multirow[t]{2}{*}{ Outcome measures } & \multicolumn{2}{|c|}{ Overall acceptance } \\
\hline & $\mathrm{OR}^{*}(95 \% \mathrm{CI})$ & P value \\
\hline \multicolumn{3}{|l|}{ Sex } \\
\hline Male & $1.28(0.37-4.41)$ & 0.68 \\
\hline Female & - & \\
\hline \multicolumn{3}{|l|}{ Age } \\
\hline 40 to 56 years old & $0.72(0.25-2.06)$ & 0.54 \\
\hline 28 to 39 years old & - & \\
\hline \multicolumn{3}{|l|}{ Socioeconomic level } \\
\hline High & $2.14(0.75-6.08)$ & 0.14 \\
\hline Low & - & \\
\hline \multicolumn{3}{|l|}{ Religion } \\
\hline Yes & $1.25(0.32-4.84)$ & 0.51 \\
\hline No & - & \\
\hline \multicolumn{3}{|l|}{ Candidate girls } \\
\hline One girl & $1.58(0.47-5.26)$ & 0.45 \\
\hline Two or more girls & - & \\
\hline \multicolumn{3}{|l|}{ Knowledge about HPV* } \\
\hline Yes & $0.96(0.26-3.48)$ & 0.6 \\
\hline No & - & \\
\hline \multicolumn{3}{|c|}{ Knowledge about the HPV* vaccine } \\
\hline Yes & $2.21(0.87-5.62)$ & 0.09 \\
\hline No & - & \\
\hline \multicolumn{3}{|c|}{ Coverage for the first dose } \\
\hline Yes & $4.08(1.56-10.68)$ & 0.003 \\
\hline No & - & \\
\hline \multicolumn{3}{|c|}{ Family member with cervical cancer } \\
\hline Yes & $0.82(0.27-2.47)$ & 0.73 \\
\hline No & - & \\
\hline
\end{tabular}

* Human papillomavirus.

* OR: odds ratio.

TABLE 1. Description of studied outcome measures among guardians. Resistencia, Chaco, 2012

\begin{tabular}{lcc}
\hline Outcome measures & $\%$ & $\mathbf{9 5 \%}$ CI \\
\hline Age (mean) & 38.3 & $36.7-39.8$ \\
Sex $\quad$ & $7.9-25.0$ \\
$\quad$ Male & $15.8 \%$ & $75.0-92.1$ \\
$\quad$ Female & $84.2 \%$ & $700-7000$ \\
\hline Monthly income in Argentine pesos (mean) & 4000 & $77.1-93.5$ \\
Religion & $86.8 \%$ & $42.6-67.4$ \\
$\quad$ Catholicism & $55.2 \%$ & $32.6-57.4$ \\
$\quad$ Evangelical Protestantism & $44.8 \%$ & $70.3-89.3$ \\
\hline Number of candidate girls & & $10.7-29.7$ \\
$\quad$ One girl & $81.1 \%$ & $75.6-92.5$ \\
$\quad$ Two or more girls & $18.9 \%$ & $40.7-64.4$ \\
Knowledge about HPV & $85.5 \%$ & $34.5-57.9$ \\
Knowledge about the HPV vaccine & $52.7 \%$ & $14.2-34.6$ \\
Coverage for the first dose & $46.1 \%$ & \\
Family member with cervical cancer & $23.3 \%$ & \\
\hline
\end{tabular}

* Human papillomavirus. 
It is worth noting that our study found no association between education level and acceptability, probably because the socioeconomic and education level of survey respondents were rather homogeneous considering that respondents belonged to a confined area of the city.

Having a family history of cancer was not associated with a greater vaccine acceptance. However, this finding is contrary to what was reported by Ogilvie et al. in 2010, who described that parents who had a family member with cervical cancer were more likely to accept HPV vaccination (OR: $1.5,95 \%$ CI: 1.1-2.1)..$^{10}$

In general, the proportion of immunized girls varies between and within countries, as well as in relation to continuity of immunization with the second dose. For example, a survey administered among parents of almost 3000 girls aged between 12 and 13 years old in Manchester (United Kingdom) showed a vaccination coverage of $70.6 \%$ for the first dose,$^{17}$ while Fang et al. reported, based on a national American survey (HINTS), a 37\% coverage in that population. ${ }^{12}$

As per the ProNaCEI data, average coverage for the complete immunization schedule in Argentina was estimated to be $50.2 \%$ for the cohort of girls born in 2000-2001, and it was lower in the province of Chaco. ${ }^{18}$ This finding is consistent with our results, which reflect the need to implement strategies aimed at improving the level of coverage.

In terms of finding an explanation for causative factors of vaccine acceptability, guardians' prior knowledge about the vaccine may be a determining factor for acceptability; however, our study found no statistically significant association. ${ }^{10-13}$
It might be interesting to look into the reasons for which guardians refuse vaccination and explore other outcome measures, such as confidence in physicians or the health care system and communication between guardians and girls regarding sexuality from a qualitative perspective. ${ }^{16}$ Another factor to be studied might be the criterion of pediatricians who provide care to this population and who may be influenced at the time of advising girls' guardians.

It is very important to improve immunization coverage levels in Argentina. In this regard, some international experiences to improve immunization adherence may be of help. In Canada, specifically in British Columbia, a school-based immunization program was implemented. Trained nurses administered the vaccine to girls during school days. This strategy was accompanied by online parental education campaigns, brochures and community discussions to identify and address myths around HPV vaccination. ${ }^{10}$

A potential limitation to our study might be that it only considered guardians of girls attending public schools, leaving out private sector facilities.

However, beyond its limitations, we expect that this pilot study serves as the basis for future, larger scale and in-depth applications of studied outcome measures. At the same time, it is a reliable instrument to measure the rate of acceptance of a new vaccine introduced in the national immunization schedule in settings where there is a high prevalence of cervical cancer.

\section{CONCLUSIONS}

Data herein analyzed reveal a low rate of acceptance, consistent with the level of coverage

TABLE3. Multivariate analysis of studied outcomemeasures and overallacceptanceamong guardians. Resistencia, Chaco, 2012. N=66

\begin{tabular}{|c|c|c|c|}
\hline Outcome measures & OR* (adjusted) & $95 \% \mathrm{CI}^{*}$ & $P$ value \\
\hline $\mathrm{HPV}^{*}$ vaccination coverage for the first dose (yes/no) & 8.02 & 2.29-28.01 & 0.0011 \\
\hline Knowledge about the HPV* vaccine (yes/no) & 1.13 & $0.36-3.52$ & 0.83 \\
\hline Knowledge about HPV* (yes/no) & 0.41 & $0.07-2.27$ & 0.31 \\
\hline Socio-economic level (middle/low) & 2.94 & $0.85-10.17$ & 0.08 \\
\hline Age (years) & 1.02 & $0.93-1.12$ & 0.58 \\
\hline Sex (male/female) & 1.26 & $0.30-5.27$ & 0.74 \\
\hline Family member with cervical cancer (yes/no) & 1.13 & $0.29-4.37$ & 0.85 \\
\hline Candidate girls for the vaccine (one/two or more) & 1.61 & $0.34-7.62$ & 0.54 \\
\hline Religion (yes/no) & 2.86 & $0.53-15.39$ & 0.21 \\
\hline
\end{tabular}

* Human papillomavirus.

* OR: odds ratio. 
for the first dose as reported by guardians. However, no demographic or psychosocial characteristic was associated with the guardians' decision to have their girls receive the HPV vaccine.

\section{REFERENCES}

1. Resolución 563/2011. Boletín Oficial de la República Argentina N. ${ }^{\circ} 32149,3$ de mayo de 2011. [Accessed on: August 26, 2015]. Available at: http://www.boletinoficial. gov.ar/DisplayPdf.aspx?s=BPBCF\&f=20110513.

2. Mazzadi A, Paolino M, Arrossi S. Aceptabilidad y conocimientos sobre la vacunación contra el virus del papiloma humano (VPH) en médicos ginecólogos de la Argentina. SaludPublicaMex 2012;54(5):515-22.

3. Instituto Nacional del Cáncer. Estadísticas. Buenos Aires: Ministerio de Salud de la Nación; 2014. [Accessed on: August 26, 2015]. Availableat: http://www.msal.gov.ar/inc/ index.php/acerca-del-cancer/estadisticas.

4. Ciapponi A, Bardach A, Glujovsky D, Gibbons L, et al. Typespecific HPV prevalence in cervical cancer and high-grade lesions in Latin America and the Caribbean: systematic review and meta-analysis. PLoS One 2011;6(10):e25493.

5. Paavonen J, Naud P, Salmeron J, Wheeler CM, et al. Efficacy of human papillomavirus (HPV)-16/18 AS04-adjuvanted vaccine against cervical infection and precancer caused by oncogenic HPV types (PATRICIA): final analysis of a double-blind, randomised study in young women. Lancet 2009;374(9686):301-14.

6. Wheeler CM, Kjaer SK, Sigurdsson K, Iversen OE, et al. The impact of quadrivalent human papillomavirus (HPV; types $6,11,16$, and 18) L1 virus-like particle vaccine on infection and disease due to oncogenic nonvaccine HPV types in sexually active women aged $16-26$ years. J Infect Dis 2009;199(7):936-44.

7. Muñoz N, Kjaer SK, Sigurdsson K, Iversen OE, et al. Impact of human papillomavirus (HPV)-6/11/16/18 vaccine on all HPV-associated genital diseases in young women. J Natl Cancer Inst2010;102(5):325-39.

8. FUTURE II Study Group. Quadrivalent vaccine against human papillomavirus to prevent high-grade cervical lesions. N C Med J 2007;356(19):1915-27.
9. UNICEF. Informe provincia de Chaco. Las oportunidades educativas (1998-2010). [Accessedon: August 26, 2015]. Availableat:http://www.unicef.org/argentina/spanish/ Informe_provincia_de_Chaco_-_Las_oportunidades_educativas_(19982010).pdf.

10. Ogilvie G, Anderson M, Marra F, McNeil S, et al. A population-based evaluation of a publicly funded, school-based HPV vaccine program in British Columbia, Canada: parental factors associated with HPV vaccine receipt. PLoS Med 2010;7(5):e1000270.

11. Ogilvie GS, Remple VP, Marra F, McNeil SA, et al. Parental intention to have daughters receive the human papillomavirus vaccine. CMAJ 2007;177(12):1506-12.

12. Fang CY, Coups EJ, Heckman CJ. Behavioral correlates of HPV vaccine acceptability in the 2007 Health Information National Trends Survey (HINTS). Cancer Epidemiol Biomarkers Prev 2010;19(2):319-26.

13. Lazcano-Ponce E, Rivera L, Arillo-Santillán E, Salmerón J, et al. Acceptability of a human papillomavirus (HPV) trial vaccine among mothers of adolescents in Cuernavaca, Mexico. Arch Med Res 2001;32(3):243-7.

14. Marlow LA, Waller J, Wardle J. Sociodemographic predictors of HPV testing and vaccination acceptability: results from a population-representative sample of British women. J Med Screen 2008;15(2):91-6.

15. Constantine NA, Jerman P. Acceptance of human papillomavirus vaccination among Californian parents of daughters: a representative statewide analysis. J Adolesc Health 2007;40(2):108-15.

16. Wiesner C, Piñeros M, Trujillo LM, Cortés C, et al. Aceptabilidad de la vacuna contra el Virus Papiloma Humano en padres de adolescentes, en Colombia. Rev Salud Publica 2010;12(6):961-73.

17. Brabin L, Roberts SA, Stretch R, Baxter D, et al. Uptake of firsttwo doses of human papillomavirusvaccinebyadolescentschoolgirls in Manchester: a prospective cohort study. BMJ 2008;336(7652):1056-8.

18. Programa Nacional de Control de Enfermedades Inmunoprevenibles. Vacuna contra el virus del papiloma humano (VPH). Page 15. Buenos Aires: Ministerio de Salud de la Nación; 2014. [Accessedon: August 26, 2015]. Available at: http://www.msal.gov.ar/images/stories/bes/ graficos/0000000449cnt-2014-02_lineamientos-tecnicosvph-2014.pdf. 
Card number:

\section{Annex}

\section{SURVEY TO GUARDIANS OF CANDIDATE GIRLS FOR THE HPV VACCINE,} RESISTENCIA, CHACO, 2012

Please, mark with an " $X$ " the corresponding answer; only one option per question.

1. Identification of guardian type:

- Mother

- Father

- Legal tutor

2. Age (years):

3. Sex:

- Male

- Female

4. Address:

5. Telephone number (landline or mobile):

Section 1: Sociodemographic factors

6. What is the maximum education level you have attained?

- Primary education

- Secondary education

- Tertiary education

- University education

- No education

7. What is the maximum education level attained by your father?

- Primary education

- Secondary education

- Tertiary education

- University education

- No education

8. What is the employment or profession resulting in your highest source of income?

9. What is, approximately, your family household monthly income?

10. Do you practice any religion?

- Yes

- No

[If Yes] What religion?

- Catholicism

- Evangelical Protestantism

- Judaism

- Other

11. How many 11 year-old or younger daughters do you have?

- One

- Two or more

12. Has your 11 year-old daughter received any of the following vaccines? (You may check her vaccination card)

Hepatitis B

Measles, rubella and mumps vaccine

Yes

No

Does not know

DPT (acellular)

Yes

No

Does not know

Yes No

Does not know 
Section 2: Psychosocial factors

13. Have you ever heard about HPV?

- Yes

- No

14. Has your 11 year-old daughter received the HPV vaccine?

- Yes

- No

15. Has any family member or close person had cervical cancer?

- Yes

- No

- Does not know

In the following grid, choose the number that best fits your answer in the guardian's column based on the scale indicated below.

1: strongly disagree;

2: disagree;

3: neither agree nor disagree;

4: agree;

5: strongly agree.

Factor I. Attitude

1. The administration of vaccines during childhood is beneficial.

2. Having my daughter/ward vaccinated will not prevent cervical cancer.

3. Cervical cancer is a serious disease.

4. HPV vaccine is effective to prevent cervical cancer.

5. HPV vaccine is not safe.

Factor II. Subjective norm (SN)

1. The religion I practice does not allow my daughter/ward to receive a vaccine.

2. My friends or family recommend against vaccinating my daughter/ward.

3. The school, health care center or TV does not encourage vaccinating my daughter/ward.

4. Most people who are significant to me consider vaccinating their daughters/wards against HPV.

5. People in my social circle whose opinions I value do not approve the HPV vaccine.

Factor III. Perceived behavioral control (PBC)

1. It is possible that I have my daughter/ward receive the HPV vaccine.

2. It is not my decision to have my daughter/ward receive the HPV vaccine.

3. I will not make an effort to have my daughter/ward receive the HPV vaccine.

4. If I make up my mind, I will have my daughter/ward receive the HPV vaccine.

5. I am not absolutely certain that my daughter/ward will receive the HPV vaccine.

6. I have other time-consuming responsibilities related to work and additional activities that hinder the possibility of having my daughter/ward receive the HPV vaccine.

7. I would have my daughter/ward receive the HPV vaccine if it meant that she cannot continue attending school or implied a penalty.

\section{Factor IV. Intention}

1. I have an intention to have my daughter/ward receive the HPV vaccine this year to prevent cervical cancer. 